\title{
DISCUSSION
}

\section{THE PSYCHOLOGY OF ADVERTISING}

A recent review ${ }^{1}$ of Strong's The Relative Merit of Advertisements displays so inadequate an appreciation both of the problem of that suggestive monograph and of the tendencies of modern experimental psychology in general that I am impelled to call further attention to the work. It is much to be regretted that this book should have been reviewed by one who failed to discriminate between a personal point of view and the total content of a large and growing science; between individual inclination for certain species of problem and "the very characteristics of a psychological experiment."

From the fact that the mathematical portion of the work in question may have been puzzling to the reviewer it does not at once follow that a search for exact measurement of complex mental processes is "detrimental to good psychology." There are indeed psychologists who are temperamentally disposed to be equally shortsighted and to assert that it is just the "detailed introspection" and the "qualitative distinctions" that get nowhere. The fact is, however, that qualitative distinction and quantitative analysis are both needed in a psychology that is "good."

Two further things are also true. The first is that a piece of work which emphasizes the latter type of inquiry reflects the trend of by far the greater part of current investigation and interest. One familiar with the contents of current periodicals and recent treatises will require no proof of this fact. The second truth is that a large body of students and teachers have been convinced that a psychology which refuses to be both sterile and unstimulating, but which aspires to be adequate and serviceable in its treatment of conscious individuals, must busy itself with outcome, conduct and behavior as much as, if not even more than, with mere content and qualitative elements and patterns.

As the writer has already insisted: "A psychology which aims to be an account of behavior cannot go far without making a careful study of more complex judgments such as those of appeal and interest. Especially will this be true of a psychology which aspires to be con-

${ }^{1}$ Psychological Bulietin, March 15, 1912, p. 124. 204 
cretely serviceable. Such a psychology will find but little use for the introspective method. It will be interested, not in the momentary content of a conscious moment; nor in the descriptive character of the sensory fragment which may at the moment be the bearer of meaning; nor in the instrument, criterion or vehicle of an act of apprehension, a comparison, a feeling or a choice. It will be most of all interested in the outcome of this moment in the form of behavior, an act, a choice, a judgment, and in the character, reliability, constancy and significance which the outcome of such a mental operation bears."1

To return to the review in question, the paragraph presented by Mr. Tait as embodying the "chief results" quite ignores the real problem, which was the measurement of the relative strength of various appeals and interests, and the determination of the dependence of these measurements on such factors as commodity, sex, class and copy differences. The paragraph cites only certain interesting facts which came out as by-products in the course of the inquiry.

Not until the importance of this type of study is fully realized shall we possess a body of principles that will really convey information concerning human nature and human behavior, a knowledge which the psychology which Mr. Tait seems to have been taught has so far failed to deliver. If a personal opinion be permitted by way of contrast with that of the reviewer, the writer would like to express his conviction that pure qualitative and introspective distinctions fall as far short of an adequate psychology as the conversational description of a stomach-ache falls short of being a complete account of the laws of digestion.

It is however not clear what the reviewer means by saying "any detailed introspection is lacking." The determination to introspect and to report the introspections as such was purposely avoided, and with good reason. But the determination to introspect and to report is apparently not a sufficient criterion of introspection. Indeed one of the foremost exponents of the introspective methods has remarked: "After all, therefore, it is not so absurd as at first thought it seems, to say that we require the animal and society and the madman to introspect. . . . All three may attend; all three may report their experiences." Is a report any the less introspective, in the final sense, because it is expressed by gesture, by behavior or by arrangement or indication of stimuli, rather than vocally or graphically?

1 Judgments of Persuasiveness. Psychological Review, July, igir.

2 Titchener, $A$ Text-Book of Psychology, p. 35 . 
The reviewer was quite right when he remarked, "By a conglomeration of vague preferences under still vaguer headings, we can never reach the basis of appeal." But Strong seems to have fully realized this even before he set about his investigation. It was just this conglomeration which the psychology of appeal had previously contained, and for which "The Relative Merit of Advertisements" suggests the substitution of definite judgments and weighted comparisons, quantitatively as well as qualitatively expressed.

Whether this type of work is or is not to be called "psychological" depends of course on the idiosyncrasies of one's vocabulary. A study of the relative strength of appeals and interests, of the certainty and constancy of the judgments passed upon them, of the possibilities of the exact measurement of the relations to be found among such complex stimuli, and of individual, sex and class differences in these respects, may not fall within that field of psychological inquiry which happens to be the most interesting to one or to several particular individuals. But the science is surely larger than any one set of interests. Let us not quibble over the use of a word. Even a quibbler should observe that the subtitle of the monograph in question includes both its psychological and statistical aspects.

My purpose in writing is not to defend either the matter or the method of this pioneer work in the application of exact method to a phase of applied psychology which has hitherto been satisfied with mere generalities. These features are amply justified by the immediate results of Strong's work. My purpose is to put on record the conviction of many BuLlETiN readers that human nature is larger than any one personal point of view, and that any attempt to extend the problems, methods and applications of psychological investigation should be both welcomed and encouraged.

Columbia University

H. L. Hollingworth 